\title{
Prevalence of and factors associated with inadequate pain relief in people with knee and hip osteoarthritis: a cross-sectional population-based study
}

\section{Daniela Sofia Albino Costa ( $\nabla$ dcosta.ft@gmail.com )}

NOVA National School of Public Health

\section{Eduardo B Cruz}

Physiotherapy Department, School of Health, Polytechnic Institute of Setúbal

\section{David G Lopes}

EpiDoC Unit, CEDOC, NOVA Medical School, Universidade NOVA de Lisboa

\section{Catarina Nunes Silva}

EpiDoC Unit, CEDOC, NOVA Medical School, Universidade NOVA de Lisboa

\section{Ana Rita Henriques}

EpiDoC Unit, CEDOC, NOVA Medical School, Universidade NOVA de Lisboa

\section{Diogo Luis}

Physiotherapy Department, School of Health, Polytechnic Institute of Setúbal

\section{Jaime Branco}

EpiDoC Unit, CEDOC, NOVA Medical School, Universidade NOVA de Lisboa

\section{Helena Canhão}

EpiDoC Unit, CEDOC, NOVA Medical School, Universidade NOVA de Lisboa

\section{Ana M Rodrigues}

EpiDoC Unit, CEDOC, NOVA Medical School, Universidade NOVA de Lisboa

\section{Research Article}

Keywords: osteoarthritis, pain management, pharmacological therapies, non-pharmacological therapies

Posted Date: February 16th, 2022

DOI: https://doi.org/10.21203/rs.3.rs-1350495/v1

License: (c) (i) This work is licensed under a Creative Commons Attribution 4.0 International License. Read Full License 
Version of Record: A version of this preprint was published at Osteoarthritis and Cartilage on April 1st, 2022. See the published version at https://doi.org/10.1016/j.joca.2022.02.009. 


\section{Abstract}

Background: Pain due to knee or hip osteoarthritis (HKOA) is the most common symptom for seeking health care given its interference on daily activities, social and occupational participation. The goal of this study is to estimate the prevalence of inadequate pain relief (IPR) among people with hip and/or knee osteoarthritis (HKOA), characterize this population and identify factors associated with IPR, and compare therapeutic strategies used by people with IPR versus adequate pain relief (APR).

Methods: We analyzed a representative sample of 1081 participants with a validated diagnosis of HKOA, from the population-based study EpiReumaPt. Sociodemographic, lifestyle and health-related data were collected in a structured interview. Pain intensity (NPRS) data were collected in a medical appointment. IPR was defined as a mean pain intensity in the previous week of $\geq 5$ points on 11-point numeric pain rating scale. Intake of regular medication for pain relief (last month), physiotherapy and surgery were considered as therapies for pain management. The factors associated with IPR were analyzed with logistic regression $(\mathrm{p}<0.05,95 \% \mathrm{Cl})$. To assess the effects of inadequate pain relief in the HOOS/KOOS activities of daily living and quality of life subscales and in the presence of anxiety and depression symptoms, linear and logistic regression were used. All analysis were weighted.

Results: The estimated prevalence of IPR among people with HKOA was $68.8 \%$. IPR was associated with being female (odds ratio $(O R)=2.36, p<0.01)$, being overweight $(O R=1.84, p=0.035)$ or obese $(O R=2.26$, $\mathrm{p}=0.006)$, and having multimorbidity $(\mathrm{OR}=2.08, \mathrm{p}=0.002)$. People with IPR reported worse performance in activities of daily living and lower quality of life ( $b=-21.28, p<0.001$ and $b=-21.19, p<0.001$, respectively) than people with APR. People with IPR consumed more NSAIDs $(22.0 \%, p=0.003)$, opioids (4.8\%, $p=0.008)$, paracetamol $(2.7 \%, p=0.033)$, and overall analgesics $(7.3 \%, p=0.013)$ than people with APR. A higher proportion of people with IPR underwent physiotherapy $(17.5 \%, p=0.002)$ than people with APR.

Conclusion: These results indicate that most people with HKOA have poor control of pain, highlighting the need for further research and implementation of effective interventions.

\section{Introduction}

Osteoarthritis (OA) is the most common joint disease, affecting more than 300 million people worldwide. The hip and knee are the most affected joints and are responsible for 9.6 million years lived with disability (1). The direct annual costs of hip and/or knee OA (HKOA) per patient are estimated at 6.7K€ worldwide, reaching $10.8 \mathrm{~K} €$ if total joint replacement surgery is considered (2), and indirect annual costs per patient are estimated at $0.2 \mathrm{~K}-12.3 \mathrm{~K} €$. In Portugal, indirect costs represent $0.4 \%$ of the national gross domestic product (3). Moreover, the incidence of total joint replacement surgery in Portugal has increased by $20 \%$ annually since 1990 and is the highest growth rate among Organisation for Economic Cooperation and Development countries (4).

People with HKOA often live with chronic pain, physical disability, and mental health and sleep problems, which impairs their quality of life (QoL) and prevents their participation in social and occupational 
activities (5). Pain is the most disabling symptom of $O A$ and a major driver of clinical decision-making and healthcare resource use (5). Pain severity is more indicative of functional impairment than radiographic severity $(6-8)$ and is strongly associated with disability, medication use $(9,10)$, healthcare resource use, impact on daily and occupational activities, loss of productivity, early retirement, and absenteeism $(11,12)$. Moreover, poor pain management is a major predictor of total joint replacement surgery (13). Recent literature raises concerns over the poor control of pain and low QoL among people with HKOA $(10,14)$, as current management strategies are focused on symptomatic control, involving medication as first-line intervention and an over-prescription of opioids $(14,15)$. Additionally, the use of end-stage interventions such as surgery is becoming more common, even among people with early-stage OA $(14,15)$.

Information on pain control, offered interventions, and factors associated with inadequate pain relief (IPR) among Portuguese people with HKOA is scarce but is crucial for evaluating current patient management strategies. Therefore, the aims of this study were to: 1 ) estimate the prevalence of IPR among Portuguese people with HKOA, 2) characterize the HKOA population in terms of sociodemographic, lifestyle, and health-related variables and identify factors associated with IPR; and 3) compare performance in activities of daily living (ADL), QoL, anxiety and depression symptoms, and therapies used between people with IPR versus people with adequate pain relief (APR). This knowledge will help determine whether current care effectively controls symptoms among people with HKOA in Portugal and whether improvements in offered interventions are needed.

\section{Methods}

\section{Data source}

We analyzed data from EpiReumaPt, a national cross-sectional, population-based study with a representative sample of the Portuguese population that aimed to analyze the burden of rheumatic and musculoskeletal diseases (RMDs) in Portugal. As described in detail elsewhere (16), participant recruitment was conducted between September 2011 and December 2013 using a random selection of private households in Portugal stratified by administrative territorial units (NUTS II: Norte, Centro, Lisboa and Vale do Tejo, Alentejo, Algarve, Azores, and Madeira) and the size of the population within each locality. In each household, an individual $\geq 18$ years old with permanent residence and the most recently celebrated birthday was selected to participate in the study. In total, 28,502 households were contacted, 8,041 individuals refused to participate, and 10,661 were included in the study. The EpiReumaPt population was similar to the Portuguese population (Census 2011) in age strata, sex, and NUTII distribution (16).

EpireumaPt data collection was performed using a three-staged approach. In the first stage, participants completed a face-to-face interview to collect sociodemographic and health-related information and to screen for RMDs. Interviews were conducted by a team of non-medical healthcare professionals trained for this purpose, and data were collected using a computer-assisted personal interview system. Screening 
was considered positive if a participant mentioned a previously known RMD, if any algorithm in the screening questionnaires was positive, or if the participant reported muscle, vertebral, or peripheral joint pain in the previous 4 weeks. When the overall performance of the RDM screening algorithm was evaluated using final diagnosis after the third stage as the gold standard, its sensitivity and specificity were $98 \%$ and $22 \%$ and positive and negative predictive value were $85 \%$ and $71 \%$, respectively.

In the second stage, participants who screened positive for at least one RMD $(n=7,451)$ and approximately $20 \%$ of participants who screened negative for RMDs $(n=701)$ were invited to a clinical appointment at the primary care center of the participant's neighborhood. Participants were seen by a multidisciplinary team consisting of a rheumatologist, X-ray technician, and nurse. Clinical assessment consisted of a structured evaluation, laboratory tests, and imaging exams, if needed, to establish a diagnosis and evaluate disease-related information. According to participants' complaints, simple X-rays were performed in 122 hips and 479 knees, among other joints. Rheumatologists were blind to prior health-related data. Of the participants in the second stage, 4,275 did not attend the clinical appointment. Therefore, at the end of the second stage, there were 3,877 clinical observations: 3,198 participants received an RMD diagnosis, and 679 did not receive an RMD diagnosis.

In the third stage, three experienced rheumatologists reviewed all data and validated the RMD diagnosis. Diagnostic agreement among the three rheumatologists was $98.3 \%$, with a Cohen's K coefficient of 10.87 (95\% confidence interval $(\mathrm{Cl}): 0.83,0.91)(16)$. When data were insufficient to fulfill international classification criteria for an RMD, five rheumatologists met to reach agreement on the final diagnosis. When doubts persisted, the opinion of the rheumatologist who performed the clinical assessment in the second stage prevailed. A total of 1,087 participants had a validated diagnosis of HKOA, 199 had a validated diagnosis of hip OA, and 981 had a validated diagnosis of knee OA (Figure 1).

-Figure 1 should be placed here-

\section{Study population}

This study included participants of EpiReumaPt with validated a diagnosis of HKOA according to American College of Rheumatology criteria $(17,18)$.

\section{Case definition and measurement}

Mean pain intensity in the previous week, measured on a 11-point numeric pain rating scale in the second stage of EpiReumaPt, was used to categorize participants with HKOA into APR ( $<5$ points) and IPR ( $\geq 5$ points), which was validated by Zelman et al. (2003) using the question 5 of Brief Pain Inventory scale, as the average pain in the previous week on an 11-point NPRS. The optimal cut-off point found for manageable day pain in $O A$ was $5(F(7,9)=7.08, p<0.001)(19)$. When both the hip and knee were affected, the worst score was considered. 


\section{Sociodemographic, clinical, and lifestyle variables}

Sociodemographic, clinical, and lifestyle variables were collected during the first and second phases of EpiReumaPt. To assure better clinical interpretation, some variables were subjected to categorical transformation.

\section{Sociodemographic and anthropometric variables}

Sociodemographic variables were age, sex, and geographic location according to NUTS II territorial units. Madeira and Azores were merged in the analysis as the Islands region. Marital status was categorized as "partner" (married or consensual union) or "no partner" (single, widowed, or divorced). Education level was categorized according to years of education completed: $<4$ years (less than primary education), 4-9 years (primary or secondary education), or $\geq 10$ years (secondary or higher education).

Body mass index (BMI) was categorized as underweight $\left(\leq 18.49 \mathrm{~kg} / \mathrm{m}^{2}\right)$, healthy weight $(\geq 18.5$ and $\left.\leq 24.99 \mathrm{~kg} / \mathrm{m}^{2}\right)$, overweight ( $\geq 25$ and $\left.\leq 29.99 \mathrm{~kg} / \mathrm{m}^{2}\right)$, or obese $\left(\geq 30 \mathrm{~kg} / \mathrm{m}^{2}\right)$.

\section{Lifestyle and clinical variables}

Lifestyle variables were alcohol intake ("no" or "occasionally or daily"), smoking habits ("never" and "occasionally or daily"), and regular exercise/sports ("yes" or "no").

The number of chronic non-communicable diseases was calculated as the numeric count of the following self-reported conditions: high blood pressure, high cholesterol, cardiac disease, diabetes mellitus, chronic lung disease, problems in the digestive tract, renal colic, neurological disease, allergies, mental or psychiatric illness, cancer, thyroid or parathyroid problems, hypogonadism, and hyperuricemia. Multimorbidity was defined as having two or more chronic non-communicable diseases (20).

In addition to pain intensity, other clinical variables were considered: performance in ADL, QoL, and the presence of depression and/or anxiety symptoms. Performance in ADL and QoL related to HKOA were evaluated with the Portuguese version of the Knee Injury and Osteoarthritis Outcome Scale (KOOS) (21) and Hip Disability and Osteoarthritis Outcome Scale (HOOS) (22). These self-reported outcome measures evaluate short- and long-term consequences of HKOA in five dimensions: pain, symptoms, ADL, sports and leisure, and QoL. For this study, we used only the HOOS/KOOS ADL and HOOS/KOOS QoL subscales. Scores for each dimension were transformed on a 0-100 scale, with 0 representing extreme hip/knee problems and 100 representing no hip/knee problems $(21,22)$. For both subscales, if more than one joint was affected, the worst score was considered.

Anxiety and depression symptoms were evaluated using the Hospital Anxiety and Depression Scale subscales for depression (HADS-D) and anxiety (HADS-A). Both scales have a range of 0 to 21, with higher values representing more severe symptoms of anxiety or depression. Final HADS-A and HADS-D 
scores were categorized using validated cut-offs as: "with anxiety" (HADS-A $\geq 11$ ) or "without anxiety" (HADS-A <11) and "with depression" (HADS-D $\geq 11$ ) or "without depression" (HADS-D <11) (23).

\section{Use of therapies}

Information on pharmacological therapies, defined as daily medications taken in the previous month, was collected in the first-stage interviews. Medication for pain relief was classified according to the Anatomical Therapeutic Chemical Classification System as: glucosamine (M01AX05); analgesics/antipyretics (N02B), specifically paracetamol (N02BE01); simple (N02A) and combined (N02AJ) opioids; non-steroidal anti-inflammatory drugs (NSAIDs; M01A); and topical agents (M02A). Information on physiotherapy attendance in the previous 12 months, was also collected in the first-stage interviews. Information on previous hip or knee surgery was collected during the second-stage clinical appointments, which occurred no more than 15 days after the first stage.

After participants were categorized into IPR and APR subgroups, weighted proportions of participants with IPR were computed taking sampling design into account as described elsewhere (16). The logit transformation method was used to calculate $95 \%$ Cls. Analysis of the proportion of participants with IPR and APR (relative and absolute frequencies) was conducted separately for participants with hip OA and those with knee OA.

Descriptive statistics were used to characterize all participants and, separately, the APR and IPR subgroups, according to sociodemographic, lifestyle, and health-related variables as well as use of therapy. Differences between subgroups were analyzed using independent samples t-tests for continuous variables and Chi-square tests for categorical variables.

We first analyzed associations between sociodemographic, lifestyle, and health-related variables and pain relief. Variables with $p<0.25$ were included in a univariate logistic regression model in a forward selection process (24) to avoid early exclusion of potentially important variables (Additional File 1). Variables with $p<0.05$ were then kept in a backward selection process to construct a multivariable model.

We next analyzed associations between IPR and clinical outcomes. Associations between IPR and HOOS/KOOS ADL and QoL subscale scores were analyzed using linear regression models adjusted for the variables retained in the multivariable model. Associations between IPR and the presence of anxiety and depression symptoms were analyzed using logistic regression models adjusted for the same variables.

Given the scarcity of data, normal and underweight BMI categories were merged into a single category $\left(<25 \mathrm{~kg} / \mathrm{m}^{2}\right)$.

All analyses were weighted and performed with SPSS 26 complex samples for MacOS (IBM Corp., Armonk, NY, USA). Statistical significance was defined as $p<0.05$. 


\section{Results}

The prevalence of IPR among people with HKOA was 68.8\%. People with IPR reported a mean pain intensity of $6.85 \pm 1.54$ on a 0 - to 10 -point numeric pain rating scale. The proportions of people with IPR who had hip OA $(n=144,69.7 \%)$ or knee OA $(n=694,69.5 \%)$ were similar (Table 1$)$.

\section{Table 1}

Prevalence of IPR and APR among people with HKOA

\begin{tabular}{|c|c|c|c|}
\hline & Total & $\begin{array}{l}\text { IPR } \\
(\text { NPRS } \geq 5)\end{array}$ & $\begin{array}{l}\text { APR } \\
(\text { NPRS <5) }\end{array}$ \\
\hline HKOA weighted prevalence $(95 \% \mathrm{Cl})$ & $100 \%$ & $68.8 \%(63.9,73.2)$ & $31.2 \%(26.8,36.1)$ \\
\hline Sample size & $n=1,035$ & $n=765$ & $n=270$ \\
\hline HKOA weighted count & $1,080,633$ & 743,130 & 337,502 \\
\hline Pain (NPRS), mean $\pm S D$ & $5.55 \pm 2.45$ & $6.85 \pm 1.54$ & $2.69 \pm 1.43$ \\
\hline Hip OA, n (\%) & $199(2.9)$ & $144(69.7)$ & $40(30.3)$ \\
\hline Knee OA, n (\%) & $981(12.4)$ & $694(69.5)$ & $247(30.4)$ \\
\hline \multicolumn{4}{|c|}{ All percentages and means \pm SDs are weighted. } \\
\hline \multicolumn{4}{|c|}{$\begin{array}{l}\text { APR, adequate pain relief; } \mathrm{Cl} \text {, confidence interval; HKOA, hip and knee osteoarthritis; IPR, inadequate } \\
\text { pain relief; NPRS, numeric pain rating scale; OA, osteoarthritis; SD, standard deviation }\end{array}$} \\
\hline
\end{tabular}

The proportion of people with IPR increased with age, reaching $73.3 \%$ in the oldest age class ( $\geq 75$ years of age) (Figure 2a). IPR was more common in females than in males (Figure 2b).

- Figure $2 \mathrm{a}$ and $2 \mathrm{~b}$ should be placed here

Mean age and age class distributions were similar between IPR and APR subgroups (Table 2). The IPR subgroup contained a larger proportion of people with a lower level of education ( $<4$ years of completed schooling) than the APR subgroup. Overweight and obesity were highly prevalent among people with HKOA and were present at similar proportions between IPR and APR subgroups.

The IPR subgroup contained smaller proportions of people who smoked or consumed alcohol daily than the APR subgroup. Although regular exercise was more common within the APR subgroup than within the IPR subgroup, this difference was not significant. The presence of multimorbidity was more common within the IPR subgroup than within the APR subgroup. 


\section{Table 2}

Sociodemographic, lifestyle, and health-related variables for people with HKOA 


\begin{tabular}{|c|c|c|c|c|}
\hline & $\begin{array}{l}\text { Total } \\
n=1,035\end{array}$ & $\begin{array}{l}\text { IPR } \\
n=765\end{array}$ & $\begin{array}{l}\text { APR } \\
n=270\end{array}$ & $p$-value ${ }^{a}$ \\
\hline Age (mean $\pm S D)$ & $64.33 \pm 12.90$ & $65.32 \pm 12.04$ & $62.17 \pm 14.38$ & 0.091 \\
\hline$<45$ years, $n(\%)$ & $38(6.1)$ & $24(4.3)$ & $14(10.2)$ & \multirow[t]{5}{*}{0.265} \\
\hline $45-54$ years, $n(\%)$ & $138(6.0)$ & 98 (15.7) & $40(17.4)$ & \\
\hline 55-64 years, n (\%) & $279(23.2)$ & 209 (23.9) & $70(21.7)$ & \\
\hline 65-74 years, n (\%) & 351 (31.3) & $261(31.4)$ & $90(30.9)$ & \\
\hline$\geq 75$ years, $n(\%)$ & $229(23.2)$ & $173(24.7)$ & $56(19.8)$ & \\
\hline Female sex, n (\%) & $744(65.4)$ & $571(72.2)$ & $173(50.5)$ & $<0.001$ \\
\hline \multicolumn{4}{|l|}{ Geographic location, n (\%) } & \multirow[t]{7}{*}{0.478} \\
\hline North & $281(35.6)$ & $205(36.0)$ & $76(34.8)$ & \\
\hline Centre & $255(27.8)$ & $180(26.2)$ & 75 (21.4) & \\
\hline Lisbon & $171(23.7)$ & $121(23.4)$ & $50(24.4)$ & \\
\hline Alentejo & $69(6.4)$ & $53(7.0)$ & $16(5.1)$ & \\
\hline Algarve & $22(1.9)$ & $18(2.3)$ & $4(1.1)$ & \\
\hline Islands & $237(4.6)$ & $188(5.3)$ & $49(3.3)$ & \\
\hline \multicolumn{5}{|l|}{ Marital status, n (\%) } \\
\hline With partner & $662(63.8)$ & 477 (64.0) & 185 (63.3) & 0.893 \\
\hline \multicolumn{4}{|l|}{ Years of education, $n$ (\%) } & \multirow[t]{4}{*}{0.024} \\
\hline$<4$ years & $257(23.0)$ & $208(26.6)$ & $49(15.1)$ & \\
\hline $4-9$ years & $652(62.2)$ & $474(58.9)$ & 178 (68.9) & \\
\hline$\geq 10$ years & $124(14.8)$ & $82(14.2)$ & $42(16.0)$ & \\
\hline \multicolumn{4}{|l|}{ BMI, n (\%) } & \multirow{4}{*}{0.067} \\
\hline Underweight/normal weight & $173(21.1)$ & $114(18)$ & $59(27.8)$ & \\
\hline Overweight & $404(43.4)$ & $294(43.5)$ & $110(43.3)$ & \\
\hline Obese & $381(35.4)$ & 297 (38.5) & $84(28.8)$ & \\
\hline \multicolumn{5}{|l|}{ Lifestyle factors, n (\%) } \\
\hline Smoker & $75(10.9)$ & $47(7.9)$ & $28(17.3)$ & 0.015 \\
\hline Daily alcohol intake & $225(28.5)$ & $152(24.5)$ & $73(37.1)$ & 0.016 \\
\hline
\end{tabular}




\begin{tabular}{|lllll|} 
Regular exercise & $220(21.5)$ & $146(19.4)$ & $74(26.2)$ & 0.116 \\
\hline Multimorbidity, $\mathbf{n ( \% )}$ & $783(73.8)$ & $608(79.4)$ & $175(61.5)$ & $<0.001$
\end{tabular}

All percentages and means \pm SDs are weighted.

${ }^{a} \mathrm{p}$-value from independent samples t-tests for continuous variables and Chi-square tests for categorical variables. Significance level $(p<0.05)$ based on adjusted $F$.

APR, adequate pain relief; BMI, body mass index; HKOA, hip and knee osteoarthritis; IPR, inadequate pain relief; SD, standard deviation

When analyzing associations between IPR and sociodemographic, lifestyle, and health-related variables, being female, being overweight or obese, and having multimorbidity were independently associated with IPR (Table 3).

\section{Table 3}

Multivariable model including factors associated with IPR in people with HKOA

\begin{tabular}{|c|c|c|}
\hline & IPR vs. APR & p-value \\
\hline & \multicolumn{2}{|l|}{ OR (95\% Cl) } \\
\hline \multicolumn{3}{|c|}{ Variables included } \\
\hline Female sex ${ }^{a}$ & 2.32 (1.50 to 3.57$)$ & $<0.001$ \\
\hline \multicolumn{3}{|l|}{$\mathrm{BMI}^{\mathrm{b}}$} \\
\hline Overweight & 1.84 (1.04 to 3.25$)$ & 0.035 \\
\hline Obese & 2.26 (1.27 to 4.02$)$ & 0.006 \\
\hline Multimorbidityc & 2.07 (1.33 to 3.20$)$ & 0.001 \\
\hline \multicolumn{3}{|c|}{$\begin{array}{l}n=1,009 .{ }^{\text {a }} \text { Reference class: male sex; }{ }^{b} \text { Reference class: underweight/normal weight; }{ }^{c} \text { Reference class: } \\
\text { no multimorbidity. Wald } F(5)=8.08, p<0.001 \text {; Nagelkerke Pseudo } \mathrm{R}^{2}=0.125 \text {. }\end{array}$} \\
\hline \multicolumn{3}{|c|}{$\begin{array}{l}\text { APR, adequate pain relief; BMI, body mass index; } \mathrm{Cl} \text {, confidence interval; HKOA, hip and knee } \\
\text { osteoarthritis; IPR, inadequate pain relief; OR, odds ratio }\end{array}$} \\
\hline
\end{tabular}

When adjusting for sex, BMI, and multimorbidity, significant negative associations between IPR and HOOS/KOOS ADL and QoL scores remained (Table 4). Thus, people with IPR were more likely to have worse HOOS/KOOS ADL and QoL scores than people with APR. Although there was a significant association between IPR and anxiety symptoms in the unadjusted model, no significant association was found in the adjusted model.

\section{Table 4}


HOOS/KOOS ADL and QoL subscale scores and anxiety and depression symptoms in people with HKOA and IPR or APR

\begin{tabular}{|c|c|c|c|c|c|c|c|c|}
\hline $\begin{array}{l}\text { Sample size } \\
\text { and } \\
\text { weighted } \\
\text { prevalence } \\
(\%)\end{array}$ & $\begin{array}{l}\text { Total } \\
n=1,035 \\
(100 \%)\end{array}$ & $\begin{array}{l}\text { IPR } \\
n=765 \\
(68.4 \%)\end{array}$ & $\begin{array}{l}\text { APR } \\
n=270 \\
(31.6 \%)\end{array}$ & & $\begin{array}{l}\text { b } \\
(95 \% \\
\text { Cl) }\end{array}$ & $\begin{array}{l}\mathrm{p}- \\
\text { value }\end{array}$ & $\begin{array}{l}\text { Adjusted b } \\
(95 \% \mathrm{Cl})\end{array}$ & $\begin{array}{l}\mathrm{p}- \\
\text { value }\end{array}$ \\
\hline \multirow{2}{*}{$\begin{array}{l}\text { HOOS/KOOS } \\
\text { ADL, } \\
\text { mean } \pm S D\end{array}$} & 66.00 & 58.36 & 83.06 & \multirow[t]{2}{*}{ IPR } & -24.70 & \multirow[t]{2}{*}{$<0.001$} & -21.28 & \multirow[t]{2}{*}{$<0.001$} \\
\hline & \pm 23.08 & \pm 21.31 & \pm 16.96 & & $\begin{array}{l}(-28.60 \\
-20.80)\end{array}$ & & $\begin{array}{l}(-24.81, \\
-17.76)\end{array}$ & \\
\hline \multirow{4}{*}{$\begin{array}{l}\text { HOOS/KOOS } \\
\text { QoL, } \\
\text { mean } \pm S D\end{array}$} & 50.55 & 43.09 & 67.00 & \multirow[t]{4}{*}{ IPR } & -23.91 & \multirow[t]{2}{*}{$<0.001$} & -21.19 & \multirow[t]{2}{*}{$<0.001$} \\
\hline & \pm 22.45 & \pm 19.37 & \pm 19.88 & & $\begin{array}{l}(-28.31 \\
-19.51)\end{array}$ & & $\begin{array}{l}(-25.22, \\
-17.16)\end{array}$ & \\
\hline & & & & & $\begin{array}{l}\text { Crude } \\
\text { OR }\end{array}$ & $\begin{array}{l}\mathrm{p}- \\
\text { value }\end{array}$ & $\begin{array}{l}\text { Adjusted } \\
\text { OR (95\% } \\
\text { Cl) }\end{array}$ & $\begin{array}{l}\mathrm{p}- \\
\text { value }\end{array}$ \\
\hline & & & & & $\begin{array}{l}(95 \% \\
\mathrm{Cl})\end{array}$ & & & \\
\hline \multirow{2}{*}{$\begin{array}{l}\text { Anxiety } \\
\text { symptoms, n } \\
\text { (\%) }\end{array}$} & \multirow{2}{*}{$\begin{array}{l}198 \\
(18.1)\end{array}$} & \multirow{2}{*}{$\begin{array}{l}161 \\
(20.6)\end{array}$} & \multirow{2}{*}{$\begin{array}{l}37 \\
(12.8)\end{array}$} & \multirow[t]{2}{*}{ IPR } & 1.76 & \multirow[t]{2}{*}{0.020} & 1.23 & \multirow[t]{2}{*}{0.395} \\
\hline & & & & & $\begin{array}{l}(1.09 \\
2.83)\end{array}$ & & $\begin{array}{l}(0.77 \\
1.97)\end{array}$ & \\
\hline \multirow{2}{*}{$\begin{array}{l}\text { Depression } \\
\text { symptoms, n } \\
\text { (\%) }\end{array}$} & \multirow{2}{*}{$\begin{array}{l}162 \\
(16.5)\end{array}$} & \multirow{2}{*}{$\begin{array}{l}130 \\
(18.1)\end{array}$} & \multirow{2}{*}{$\begin{array}{l}32 \\
(12.9)\end{array}$} & \multirow[t]{2}{*}{ IPR } & 1.49 & \multirow[t]{2}{*}{0.235} & 1.11 & \multirow[t]{2}{*}{0.744} \\
\hline & & & & & $\begin{array}{l}(0.77 \\
2.86)^{\prime}\end{array}$ & & $\begin{array}{l}(0.59 \\
2.12)\end{array}$ & \\
\hline
\end{tabular}

All percentages and means \pm SDs are weighted. $b$ and OR are adjusted for sex, obesity, and multimorbidity.

$\mathrm{ADL}$, activities of daily living; APR, adequate pain relief; $\mathrm{Cl}$, confidence interval; $\mathrm{HKOA}$, hip and knee osteoarthritis; HOOS, Hip Disability and Osteoarthritis Outcome Scale; IPR, inadequate pain relief; KOOS, Knee Injury and Osteoarthritis Outcome Scale; OR, odds ratio; QoL, quality of life; SD, standard deviation

Overall, NSAIDs, analgesics, and physiotherapy were the most used therapies by people with HKOA (Table 5). Higher proportions of people within the IPR subgroup regularly took NSAIDS, simple opioids, and analgesics, specifically paracetamol, than within the APR subgroup. Physiotherapy was also more commonly used by people with IPR than by people with APR. There were no significant differences in the proportions of people who underwent hip or knee surgery between IPR and APR subgroups.

\section{Table 5}

Pharmacological, conservative non-pharmacological, and surgical therapies used by people with HKOA with IPR or APR 


\begin{tabular}{|c|c|c|c|c|}
\hline & Total & IPR & APR & p-value ${ }^{a}$ \\
\hline \multirow[t]{2}{*}{ Sample size and weighted prevalence } & $\mathrm{n}=1,035(100 \%)$ & $n=765$ & $\mathrm{~N}=270$ & \\
\hline & & $(68.4 \%)$ & $(31.6 \%)$ & \\
\hline \multicolumn{5}{|l|}{ Pharmacological therapies } \\
\hline \multicolumn{5}{|l|}{ Anti-inflammatory } \\
\hline NSAIDS, n (\%) & $239(19.0)$ & $194(22.0)$ & $45(12.5)$ & 0.003 \\
\hline Topical NSAIDS, n (\%) & $10(1.2)$ & $7(1.5)$ & $3(0.7)$ & 0.410 \\
\hline \multicolumn{5}{|l|}{ Opioids } \\
\hline Simple opioids, n (\%) & $49(3.7)$ & $44(4.8)$ & $5(1.3)$ & 0.008 \\
\hline Opioids combined with analgesics, $n$ (\%) & $24(1.4)$ & $22(1.8)$ & $2(0.4)$ & 0.053 \\
\hline \multicolumn{5}{|l|}{ Analgesics/antipyretics } \\
\hline Analgesics (all), n (\%) & $72(5.7)$ & $62(7.3)$ & $10(2.7)$ & 0.013 \\
\hline Paracetamol, n (\%) & $25(2.0)$ & $23(2.7)$ & $2(0.6)$ & 0.033 \\
\hline \multicolumn{5}{|l|}{ Others } \\
\hline Glucosamine, n (\%) & $65(4.7)$ & $53(5.1)$ & $12(3.9)$ & 0.438 \\
\hline \multicolumn{5}{|l|}{ Conservative non-pharmacological therapies } \\
\hline Physiotherapy, n (\%) & $152(14.9)$ & $121(17.5)$ & $31(8.9)$ & 0.002 \\
\hline \multicolumn{5}{|l|}{ Surgery } \\
\hline Hip surgery ${ }^{b}, \mathrm{n}(\%)$ & $42(18.7)$ & $29(19.1)$ & $13(17.6)$ & 0.847 \\
\hline Knee surgeryc, n (\%) & $113(13.2)$ & $82(13.4)$ & $31(13.0)$ & 0.893 \\
\hline \multicolumn{5}{|c|}{$\begin{array}{l}\text { All percentages are weighted. } \\
\text { ap-value from Chi-square tests. Significance level is based on adjusted F. bS Sub-sample with hip OA. } \\
\text { 'Sub-sample with knee OA. }\end{array}$} \\
\hline \multicolumn{5}{|c|}{$\begin{array}{l}\text { APR, adequate pain relief; } \mathrm{Cl} \text {, confidence interval; HKOA; hip and knee osteoarthritis; IPR, inadequate } \\
\text { pain relief; NSAIDS, non-steroidal anti-inflammatory drugs; OA, osteoarthritis }\end{array}$} \\
\hline
\end{tabular}

\section{Discussion}

Our results indicate that $68.8 \%$ of people with HKOA in Portugal live with IPR, which is higher than the prevalence of IPR in Mexico (53\%) (29), the Survey of Osteoarthritis Real World Therapies (SORT) cohort from six European countries (54\%) (10), and a sample of Portuguese people with knee OA included in the 
SORT cohort (51\%) (26). All three of these earlier studies included people who were $\geq 50$ years old, with knee OA, and who took analgesics regularly, which may explain why we found a higher prevalence of IPR in the present study. Moreover, our study included a representative sample of the Portuguese population who live in the community, suggesting that offered interventions do not meet the need for pain relief for more than two-thirds of the Portuguese HKOA population.

We found that people with IPR had lower education levels than people with APR. This finding is consistent with previous literature reporting that low education is associated with more severe $\mathrm{OA}$ symptoms and is a social determinant of unhealthy lifestyles and multimorbidity $(27,28)$, is a determinant of lack of access to and delay in seeking healthcare (32), and is associated with increased pain intensity over time (33).

The multivariable model showed that female sex, overweight and obesity, and multimorbidity were associated with IPR, similar to the results of the SORT study (10). Being female is associated with higher OA-related pain levels, and despite contradictory literature, studies suggest that psychosocial factors such as hypervigilance, catastrophizing, and passive coping strategies, which are highly variable across socio-cultural environments, may explain a lower pain threshold among women (30). Also, a systematic review of progression phenotypes among people with OA shows that overweight or obesity is a major factor in the progression of $O A$ and is associated with worsening of pain, loss of physical function, and structural deterioration over time (31).

Additionally, our results show that having multimorbidity was associated with IPR. Multimorbidity is associated with chronic pain in a cumulative manner (32) and is related to pain intensity in people with HKOA (33). People with multimorbidity have a higher likelihood of walking impairments, which can contribute to a worsening of $O A$ and other chronic conditions, with an additional consequence of psychological distress $(32,33)$.

We found that IPR was negatively associated with performance in ADL and QoL. Previous research reveals that within the OA population, pain severity explains most of the variability in disability and QoL (34). High pain severity may lead to fear of movement and/or avoidance behaviors, resulting in physical inactivity and less participation in social activities and leading in turn to greater physical disability, psychological distress, and reduced QoL (35).

International clinical practice guidelines recommend that topical NSAIDs be considered before oral NSAIDs in line with the least systemic exposure principle, and oral NSAIDs are strongly recommended at the lowest possible dose (36). Given the limited efficacy of paracetamol and its potentially harmful secondary effects, it is only conditionally recommended for people with OA (36). Although tramadol is conditionally recommended, non-tramadol opioids are not recommended for the management of pain in people with $O A$, and both should be used only when alternatives have been exhausted. Glucosamine is strongly not recommended for people with HKOA (36). In the present study, oral NSAIDs were the most used medication followed by analgesics/antipyretic medication, whereas topical NSAIDs were the least used pharmacological modality. 
People with IPR regularly took more medication for pain relief, namely NSAIDS, opioids, and analgesics, specifically paracetamol, than people with APR, consistent with the results of the SORT study (10). A cohort study from the Netherlands also shows that that pain severity is positively related to analgesic intake; however, the authors concluded that most reasons for analgesic prescription are unknown (37).

Even though no temporal relationships can be drawn from a cross-sectional design, this study reveals that a higher proportion of people who took daily pain medication in the previous month had IPR.

Additionally, our results suggest that medication is taken by a much lower proportion of people with OA in Portugal than in other European countries (12). The reason for this may be due to the timeframe used in different studies to define medication intake and the adherence of patients to medication regimens. In Europe, NSAIDs and opioids are prescribed to $58.9 \%$ and $35.5 \%$ of people with OA, respectively, although medication use was defined as "medication used at the moment" (12) rather than daily use in the previous month. Although randomized controlled trials show that analgesic drugs and other recommended interventions effectively manage pain in individuals with $O A$, adherence to medication and healthy lifestyle behaviors are a real-world concern that prevent the optimization of pain control in this population. A qualitative meta-ethnographic study points out that factors such as the severity of pain, perceived effect of medication, fear related to side effects, acceptability of dose regimens, education and knowledge about OA and the medication regimen, self-efficacy, and locus of control over OA influence medication adherence (38).

Regarding conservative non-pharmacological therapies used by people with HKOA, we found that $<20 \%$ of people with IPR underwent physiotherapy in the last 12 months or regularly exercised. However, current clinical guidelines recommend physiotherapy and exercise as first-line treatments that should maintained during the progression of the disease for pain management purposes $(39,40)$. Although, literature suggests that current management of people with HKOA, core non-pharmacological treatments are offered to $<50 \%$ of patients, with symptom-driven and segmented interventions (41) centered on pharmacological $(42,43)$ and surgical options (44).

\section{Limitations}

Our study has several limitations that should be considered. Due to its cross-sectional design, no causeeffect relationships can be established between IPR and sociodemographic, lifestyle, and health-related variables. Also, estimation of the proportion of people with IPR in the Portuguese population using sample weights is not free from error, although sample weights are recommended for all statistical analyses using complex samples data (45).

Although hip OA and knee OA may impose similar burdens on domains of patients' lives $(1,46)$, previous research shows that people with hip OA have more severe disease and an earlier requirement for joint replacement (47). However, we did not thoroughly investigate differences in factors associated with IPR between people with hip OA versus knee OA. 
We asked participants about their use of "regular medication". However, as people with OA often use analgesic medication sporadically for pain flares rather than daily, our results may underestimate the proportion of people that use medication for symptomatic control. Also, as physiotherapy attendance in the last 12 months was self-reported, we acknowledge the possibility that memory bias may compromise the accuracy of our results. Additionally, we did not investigate the reason for medication use or physiotherapy.

"Regular exercise" was self-reported by participants and did not consider the precise amount and intensity. Hence, our data may overestimate the proportion of people who exercised. Moreover, pain intensity is multifactorial (35), and several potentially important factors were not considered in the analysis, such as fear avoidance beliefs, catastrophizing, or coping strategies.

The analyzed data were collected in 2011-2013, but due to few specific strategies directed to RMDs in the last decade in Portugal, we cautiously believe that the current management of OA does not differ from that reflected in this study.

\section{Strengths and implications}

This is the first population-based study in Portugal analyzing outcomes of current interventions offered to community-dwelling people with HKOA. The results of this study raise concerns regarding important factors that should be further explored in future research and addressed in national health policies to optimize the outcomes of people with HKOA, namely:

1) The high proportion of people with IPR, which may suggest the ineffectiveness of current management;

2) The high proportion of people with IPR who use pharmacological and non-pharmacological therapies, which may indicate suboptimal outcomes of current interventions;

3) Besides the low proportion of people who use therapy, the interventions offered do not seem to be aligned with international recommendations $(36,39)$ considering the small proportion of people who underwent physiotherapy, exercised, and used pain medication and the large proportion of people who were overweight or obese.

\section{Conclusion}

Approximately two-thirds of the Portuguese population with HKOA have IPR, despite the higher use of medication and physiotherapy in the IPR subgroup than in the APR subgroup. Being overweight and having multimorbidity are modifiable risk factors associated with IPR. Overall, recommended management strategies appear to be offered to a small proportion of people with HKOA. These results reveal an opportunity for pain control improvement in the HKOA population and highlight the need for further research on effective pain relief interventions. 


\section{Abbreviations}

ADL: Activities of Daily Living

APR: Adequate Pain Relief

BMI: Body Mass Index

Cl: Confidence Interval

HADS-A: Hospital Anxiety and Depression Scale subscale for anxiety

HADS-D: Hospital Anxiety and Depression Scale subscale for depression

HKOA: Hip and/or Knee Osteoarthritis

HOOS: Hip Disability and Osteoarthritis Outcome Scale

IPR: Inadequate Pain Relief

KOOS: Knee Injury and Osteoarthritis Outcome Scale

NPRS: Numerical Pain Rating Scale

NSAIDs: Non-steroidal anti-inflammatory drugs

OA: Osteoarthritis

OR: Odds Ratio

QoL: Quality of Life

RMD: Rhematic and Musculoskeletal Diseases

SD: Standard Deviation

SORT: Survey of Osteoarthritis Real World Therapies

\section{Declarations}

\section{Ethical approval and consent to participate:}

The EpiReumaPt study was approved by the Ethics Committee of NOVA Medical School and the Portuguese Data Protection Authority (Comissão Nacional de Proteção de Dados). Written informed consent was obtained from all participants in accordance with the Declaration of Helsinki as described elsewhere (16). 


\section{Consent for publication:}

Not Applicable.

\section{Availability of data and materials:}

The data underlying this article were provided by the EpiDoc Unit - CEDOC by permission. Data will be shared upon request to the corresponding author with the permission of EpiDoc Unit group leaders.

\section{Competing interests:}

All authors declare no competing interests.

\section{Funding:}

This study received funding from an independent research grant (ID\#64165707) by Pfizer, and the first author received a grant from Fundação Ciência e Tecnologia, IP under the PhD grant

SFRH/BD/148420/2019. The funders were not involved in study design; collection, analysis, or interpretation of data; or writing this article or the decision to submit it for publication.

\section{Acknowledgements:}

We thank Prof. Carla Nunes (NOVA National School of Public Health - Universidade NOVA de Lisboa) for the valuable insights and discussions in the conceptualization of this project. We thank the EpiDoc Unit and EpiReumaPt team for conceptualizing, planning, and implementing the main research project. We also acknowledge the support of CHRC (UIDP/04923/2020), granted by national funds through Fundação Ciência e Tecnologia, IP.

\section{Authors' Contributions:}

$D C, D G L$, and CNS contributed to the drafting of the manuscript. DC, EBC, DL and AMR contributed to the analysis and interpretation of the data. DC, DGL, and ARH contributed to statistical analysis. $\mathrm{HC}$, JB, and AMR contributed to the conception and design of the main project (EpiReumaPt), provision of study materials, obtaining funding for the main project, administrative/logistic support, and collection of data. All authors critically revised and approved the final manuscript.

\section{References}


1. Safıri S, Kolahi A-A, Smith E, Hill C, Bettampadi D, Mansournia MA, et al. Global, regional and national burden of osteoarthritis 1990-2017: a systematic analysis of the Global Burden of Disease Study 2017. Annals of the Rheumatic Diseases. 2020 Jun;79(6):819-28.

2. Salmon JH, Rat AC, Sellam J, Michel M, Eschard JP, Guillemin F, et al. Economic impact of lower-limb osteoarthritis worldwide: a systematic review of cost-of-illness studies.Vol. 24, Osteoarthritis and Cartilage. W.B. Saunders Ltd; 2016. p. 1500-8.

3. Laires PA, Canhao H, Rodrigues AM, Eusebio M, Gouveia M, Branco JC.The impact of osteoarthritis on early exit from work: results from a population-based study. BMC Public Health. 2018;18(1):472.

4. Pabinger $\mathrm{C}$, Lothaller $\mathrm{H}$, Geissler A. Utilization rates of knee-arthroplasty in OECD countries. Osteoarthritis Cartilage. 2015;23(10):1664-73.

5. March L, Cross M, Lo C, Arden NK, Gates L, Leyland KM, et al. Osteoarthritis: A Serious Disease: Submitted to the U.S. Food and Drug Administration. 2016.

6. Cubukcu D, Sarsan A, Alkan H. Relationships between Pain , Function and Radiographic Findings in Osteoarthritis of the Knee: A Cross-Sectional Study. 2012;2012(April 2007).

7. Creamer $P$, Hochberg MC. Factors associated with functional impairment in symptomatic knee osteoarthritis. 2000;490-6.

8. Barthel HR, Peniston JH, Clark MB, Gold MS, Altman RD. Correlation of pain relief with physical function in hand osteoarthritis : randomized controlled trial post hoc analysis. 2010;1-8.

9. Kingsbury SR, Hensor EMA, Walsh CAE, Hochberg MC, Conaghan PG. How do people with knee osteoarthritis use osteoarthritis pain medications and does this change over time? Data from the Osteoarthritis Initiative. Arthritis Research \& Therapy. 2013;15(5):R106.

10. Conaghan PG, Peloso PM, Everett S v., Rajagopalan S, Black CM, Mavros P, et al. Inadequate pain relief and large functional loss among patients with knee osteoarthritis: evidence from a prospective multinational longitudinal study of osteoarthritis real-world therapies. Rheumatology (United Kingdom). 2015;54(2):270-7.

11. Dibonaventura M, Gupta S, Mcdonald M, Sadosky A, Pettitt D, Silverman S. Impact of self-rated osteoarthritis severity in an employed population: Cross-sectional analysis of data from the national health and wellness survey. 2012;1-12.

12. Kingsbury SR, Gross HJ, Isherwood G, Conaghan PG. Osteoarthritis in Europe: impact on health status, work productivity and use of pharmacotherapies in five European countries. Rheumatology (Oxford). 2014;53(5):937-47.

13. Fu K, Robbins SR, Mcdougall JJ. Osteoarthritis update - improving our understanding and management Osteoarthritis: the genesis of pain. 2020;1-8.

14. Hagen KB, Smedslund G, Osteras N, Jamtvedt G. Quality of Community-Based Osteoarthritis Care: A Systematic Review and Meta-Analysis. Arthritis Care \& Research. 2016;68(10):1443-52.

15. Hunter DJ, Bierma-Zeinstra S. Osteoarthritis. The Lancet.2019;393(10182):1745-59. 
16. Rodrigues AM, Gouveia N, da Costa LP, Eusébio M, Ramiro S, Machado P, et al.EpiReumaPt- the study of rheumatic and musculoskeletal diseases in Portugal: a detailed view of the methodology.Acta reumatologica portuguesa. 2015;40(2):110-24.

17. Altman R, Alarcón G, Appelrouth D, Bloch D, Borenstein D, Brandt K, et al.The American College of Rheumatology criteria for the classification and reporting of osteoarthritis of the hip. Arthritis and rheumatism. 1991 May;34(5):505-14.

18. Altman R, Asch E, Bloch D, Bole G, Borenstein D, Brandt K, et al. Development of criteria for the classification and reporting of osteoarthritis. Classification of osteoarthritis of the knee. Diagnostic and Therapeutic Criteria Committee of the American Rheumatism Association. Arthritis Rheum. 1986;29(8):1039-49.

19. Zelman DC, Hoffman DL, Seifeldin R, Dukes EM. Development of a metric for a day of manageable pain control: Derivation of pain severity cut-points for low back pain and osteoarthritis. Pain. 2003;106(1-2):35-42.

20. Diederichs C, Berger K, Bartels DB. The Measurement of Multiple Chronic Diseases--A Systematic Review on Existing Multimorbidity Indices. The Journals of Gerontology Series A: Biological Sciences and Medical Sciences. 2011 Mar 1;66A(3):301-11.

21. Goncalves RS, Cabri J Fau - Pinheiro JP, Pinheiro Jp Fau - Ferreira PL, Ferreira PI Fau - Gil J, Gil J, Osteoarthritis C. Reliability, validity and responsiveness of the Portuguese version of the Knee injury and Osteoarthritis Outcome Score--Physical Function Short-form (KOOS-PS). Osteoarthritis Cartilage. 2010;18(3).

22. Cavalheiro L, Gil J, Nunes S, Ferreira P, Gonçalves R. Measuring Health-Related Quality of Life in Patients With Hip Osteoarthritis and Total Hip Replacement: Adaption and Validation of the Hip Disability and Osteoarthritis Outcome Source LK 2.0 (HOOS 2.0) to the Portuguese Culture. In: 18th Annual Conference of the International Society of Quality of Life (ISOQOL 2011).2011.

23. Silva I, Pais-Ribeiro J, Cardoso H. Contributo para a adaptação da Hospital Anxiety and Depression Scale à população portuguesa com doença crónica. Psychologica. 2006;41:193-204.

24. Bursac Z, Gauss CH, Williams DK, Hosmer DW. Purposeful selection of variables in logistic regression. Source Code for Biology and Medicine. 2008;3:1-8.

25. Burgos-Vargas R, Aggarwal J, Johnson KD, Ramey D, Lozano F, Macahilig C, et al. Results from a cross-sectional, observational study to assess inadequate pain relief in patients with knee and/or hip osteoarthritis in Mexico.Reumatología Clínica (English Edition). 2021 Aug;17(7):397-403.

26. Laires PA, Laíns J, Miranda LC, Cernadas R, Rajagopalan S, Taylor SD, et al.Inadequate pain relief among patients with primary knee osteoarthritis. Revista Brasileira de Reumatologia (English Edition). 2017:57(3):229-37.

27. Luong M-LN, Cleveland RJ, Nyrop KA, Callahan LF. Social determinants and osteoarthritis outcomes. Aging health. 2012;8(4):413-37.

28. Guillemin F, Carruthers E, Li LC. Determinants of MSK health and disability - Social determinants of inequities in MSK health. Vol. 28, Best Practice and Research: Clinical Rheumatology. Bailliere Tindall 
Ltd; 2014. p. 411-33.

29. Pan F, Tian J, Aitken D, Cicuttini F, Jones G. Predictors of pain severity trajectory in older adults: a 10.7-year follow-up study. Osteoarthritis and cartilage. 2018;26(12):1619-26.

30. Hashmi JA, Davis KD. Deconstructing sex differences in pain sensitivity. Pain. 2014 Jan;155(1):103.

31. Deveza LA, Melo L, Yamato TP, Mills K, Ravi V, Hunter DJ. Knee osteoarthritis phenotypes and their relevance for outcomes: a systematic review. Osteoarthritis and Cartilage. 2017;25(12):1926-41.

32. Dominick CH, Blyth FM, Nicholas MK. Unpacking the burden: Understanding the relationships between chronic pain and comorbidity in the general population. Pain. 2012 Feb;153(2):293-304.

33. Muckelt PE, Roos E, Stokes M, McDonough S, Grønne D, Ewings S, et al. Comorbidities and their link with individual health status: A cross-sectional analysis of 23,892 people with knee and hip osteoarthritis from primary care. Journal of Comorbidity. 2020 Jan 1;10:2235042X2092045.

34. Montero A, Mulero J-F, Tornero C, Guitart J, Serrano M. Pain, disability and health-related quality of life in osteoarthritis-joint matters: an observational, multi-specialty trans-national follow-up study. Clinical Rheumatology. 2016 Sep 11;35(9):2293-305.

35. Hawker GA. Osteoarthritis is a serious disease. Clinical and experimental rheumatology. 2019;37 Suppl 1(5):3-6.

36. Kolasinski SL, Neogi T, Hochberg MC, Oatis C, Guyatt G, Block J, et al. 2019 American College of Rheumatology/Arthritis Foundation Guideline for the Management of Osteoarthritis of the Hand, Hip, and Knee. Arthritis \& Rheumatology. 2020 Feb 6;72(2):220-33.

37. Knoop J, van Tunen J, van der Esch M, Roorda LD, Dekker J, van der Leeden M, et al. Analgesic use in patients with knee and/or hip osteoarthritis referred to an outpatient center: a cross-sectional study within the Amsterdam Osteoarthritis Cohort. Rheumatology International. 2017 Oct 18;37(10):174755.

38. Dockerty T, Latham SK, Smith TO. Why don't patients take their analgesics? A meta-ethnography assessing the perceptions of medication adherence in patients with osteoarthritis. Rheumatology International. 2016 May 10;36(5):731-9.

39. Bannuru RR, Osani MC, Vaysbrot EE, Arden NK, Bennell K, Bierma-Zeinstra SMA, et al. OARSI guidelines for the non-surgical management of knee, hip, and polyarticular osteoarthritis. Osteoarthritis and Cartilage. 2019 Jun 20;27(11):1578-89.

40. Geenen R, Overman CL, Christensen R, Åsenlöf P, Capela S, Huisinga KL, et al. EULAR recommendations for the health professional's approach to pain management in inflammatory arthritis and osteoarthritis. Annals of the Rheumatic Diseases. 2018;77(6):797-807.

41. Hunter DJ. Osteoarthritis Management: Time to Change the Deck. J Orthop Sports Phys Ther. 2017:47(6):370-2.

42. Basedow M, Esterman A. Assessing appropriateness of osteoarthritis care using quality indicators: $A$ systematic review. Journal of Evaluation in Clinical Practice. 2015;21(5):782-9. 
43. Edwards JJ, Khanna M, Jordan KP, Jordan JL, Bedson J, Dziedzic KS. Quality indicators for the primary care of osteoarthritis: A systematic review. Annals of the Rheumatic Diseases. 2013;74(3):490-8.

44. Bruyere O, Honvo G, Veronese N, Arden NK, Branco J, Curtis EM, et al. An updated algorithm recommendation for the management of knee osteoarthritis from the European Society for Clinical and Economic Aspects of Osteoporosis, Osteoarthritis and Musculoskeletal Diseases (ESCEO). Semin Arthritis Rheum. 2019;

45. Lavallée P, Beaumont J-F. Why We Should Put Some Weight on Weights. In: Survey Insights: Methods from the Field, Weighting: Practical Issues and 'How to' Approach. 2015.

46. Postler A, Ramos AL, Goronzy J, Gunther KP, Lange T, Schmitt J, et al. Prevalence and treatment of hip and knee osteoarthritis in people aged 60 years or older in Germany: an analysis based on health insurance claims data. Clin Interv Aging. 2018;13:2339-49.

47. Dabare C, Le Marshall K, Leung A, Page CJ, Choong PF, Lim KK. Differences in presentation, progression and rates of arthroplasty between hip and knee osteoarthritis: Observations from an osteoarthritis cohort study-a clear role for conservative management. International Journal of Rheumatic Diseases. 2017;20(10):1350-60.

\section{Figures}


Figure 1. EpiReumaPt study flowchart

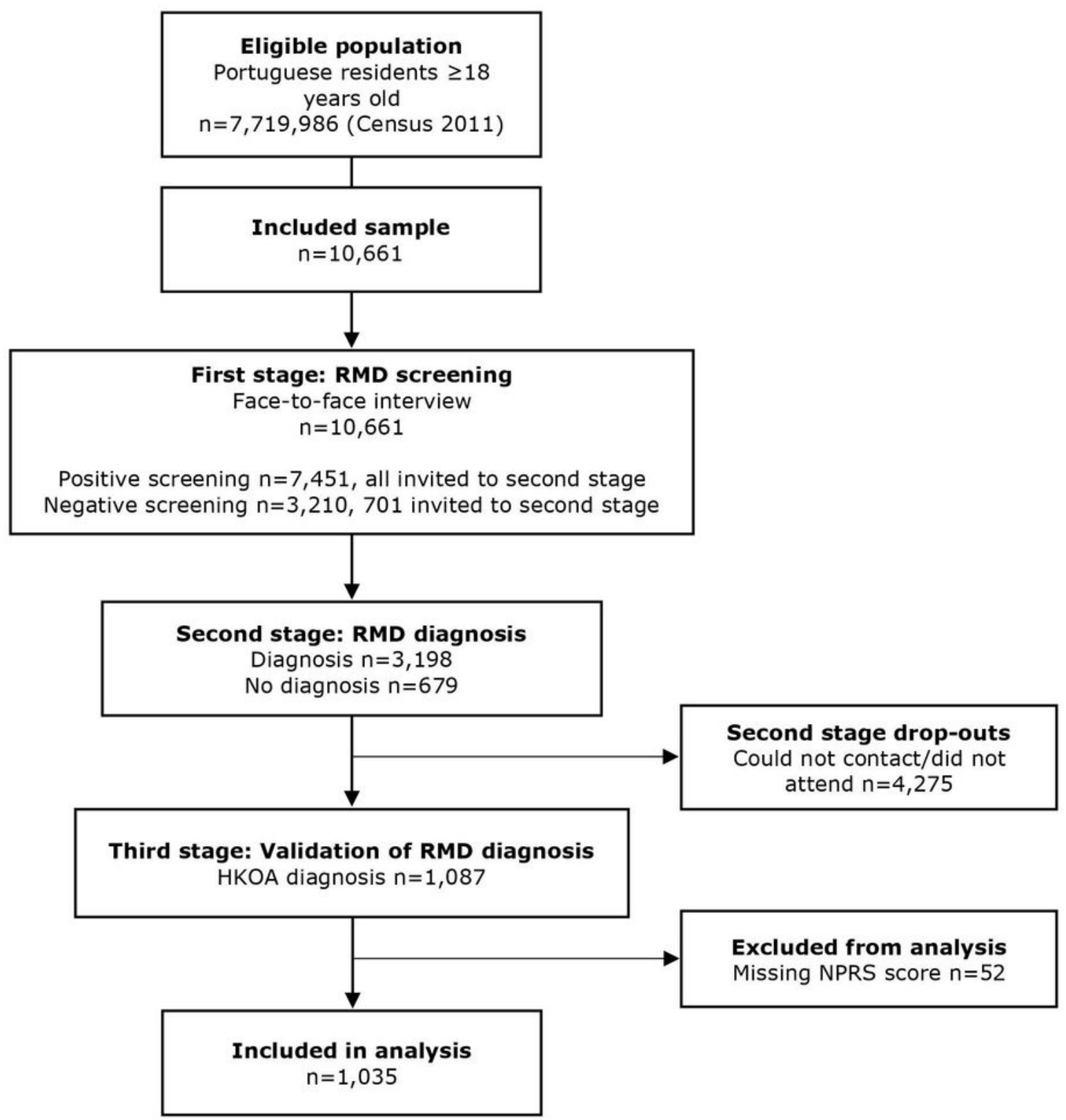

Figure 1

Please See image above for figure legend. 
Figure 2. Proportions of people with HKOA and APR or IPR by (a) age class (years) and (b) sex.

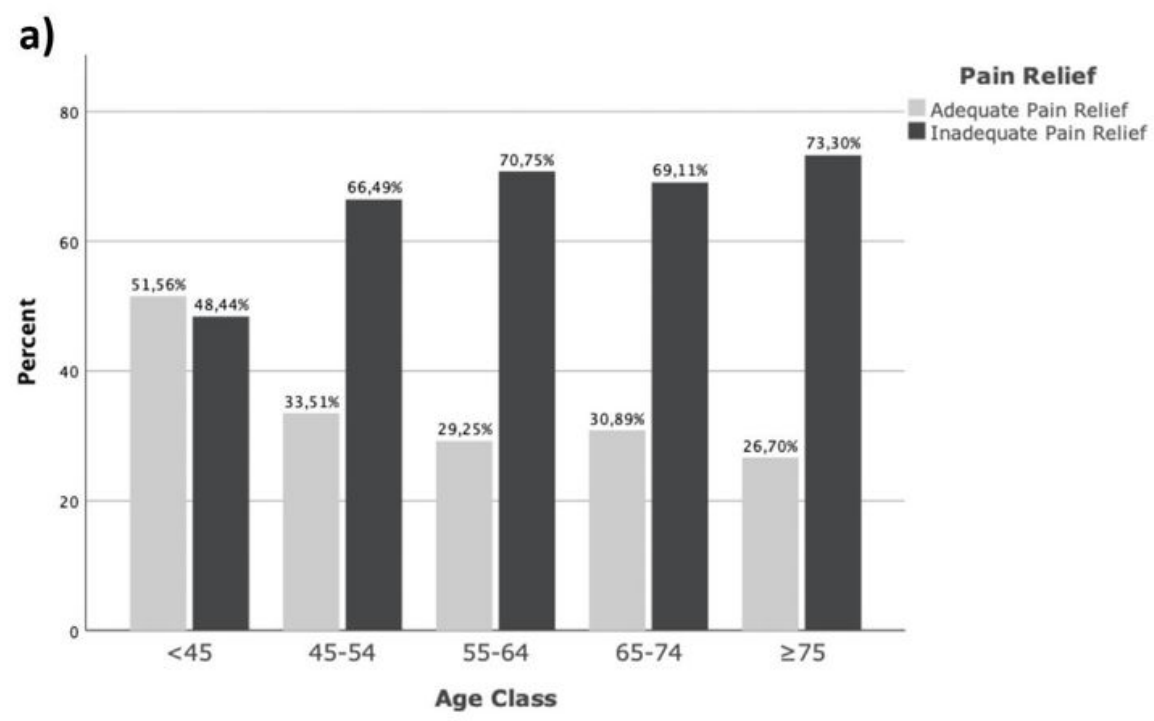

b)

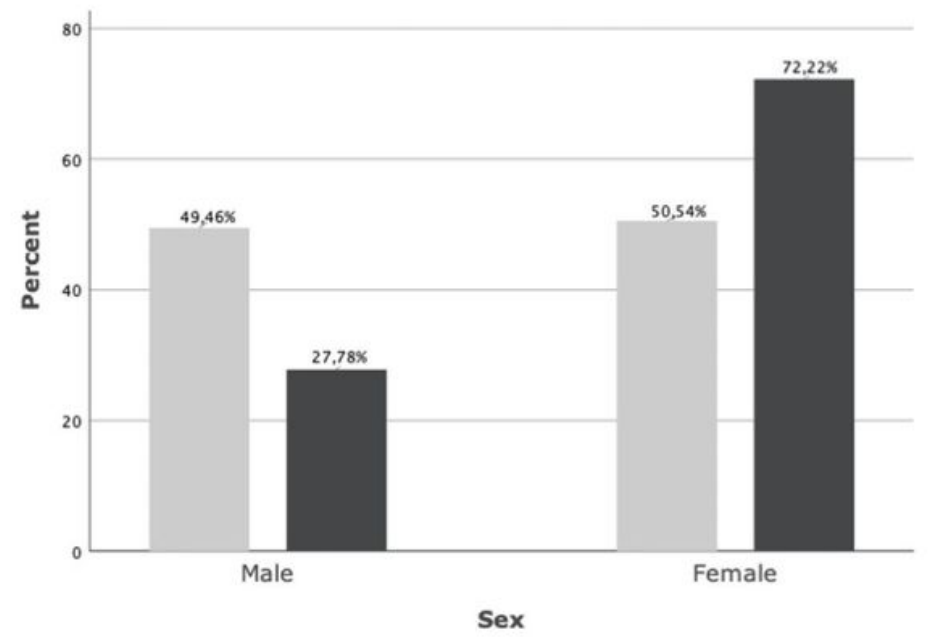

Figure 2

Please See image above for figure legend.

\section{Supplementary Files}

This is a list of supplementary files associated with this preprint. Click to download.

- Additionalfile1.docx 